\title{
CORRESPONDENCE
}

To the Editor:

Dear Sir,

\section{VERTIGO IN DIVERS}

Having been involved in Sports Medicine, both from administrative and professional sides, I tend to be aggravated by statements made by doctors whose speciality does not seem to fit in with the statements they make. I have spoken to 767 divers who have consulted me as an Ear, Nose and Throat Surgeon over the past 14 years. Their remarks have been committed in writing and in detail, during a close and interrogative interview in the calm and quiet of my private consulting room.

As far as vertigo following rupture of the ear drum is concerned, I still dispute the inevitability of its occurrence. The temperature of the water "in the sunnier climes of the Antipodes" is at present $17^{\circ} \mathrm{C}$ in the North and grades down to $11^{\circ} \mathrm{C}$ in the South at the surface. Deeper water tends to be $2.3^{\circ} \mathrm{C}$ cooler and in the winter it is up to $3^{\circ} \mathrm{C} \mathrm{cooler} \mathrm{in} \mathrm{the}$ North. As far as caloric effects on the inner ear is concerned there is little if any difference between the $12^{\circ} \mathrm{C}$ of the British Isles water and the $17^{\circ} \mathrm{C}$ summer temperature of the northern New Zealand waters.

I quoted ear drum ruptures on descent but there are others in whom it occurs on ascent and then one supposes the outgoing air keeps water out of the middle ear and vertigo is rare.

Finally I will quote 2 cases that I had under my care in Middlemore Hospital in October 1982. Both cases had a unilateral sudden sensorineural deafness and both were admitted for inpatient treatment of this calamity.

\section{Case 1}

A 27 year old male diver of 1 year standing including 80 dives, who had previously been seen 1 year before with a left haemotympanum from diving and from which a full recovery had been made, attended because of a blocked left ear with a humming sound. This came on after surfacing from a $4 \mathrm{~m}$ dive 14 hours previously during which dive he had some difficulty in equalising his middle ear pressures. He did have a 5 second dizziness on surfacing with a minor rotary element. His hearing on the right was normal and on the left there was an average $55 \mathrm{db}$ loss for frequencies of $1 / 2,1$ and $2 \mathrm{Khz}$. He was admitted to hospital for medical treatment of sudden deafness which was unchanged after 4 days, and so his middle ear was opened, searching for a round or oval window rupture. No fluid was seen to come from these regions when compressing the jugular veins but the round window membrane was seen to bulge. One week later the tinnitus was a quieter ringing and the hearing $40 \%$ better. Two weeks after treatment he gained his permanent hearing improvement which left him with normal hearing apart from a $\mathbf{4 0} \mathrm{db}$ loss in the $1 / 2 \mathrm{Khz}$ note, a hearing handicap from $9 \%$ to $1.7 \%$.

\section{Case 2}

A 19 year old female of 3 months experience on her third dive since her diving course was seen 2 days before case 1 , after a $13 \mathrm{~m}$ dive with a quick ascent. She developed vertigo for 24 hours, a ringing in the right ear and a loss of balance for 3 days and she consulted me on the 10th day post-incident. She was admitted to hospital for medical treatment but continued with her deafness and some imbalance. Under general anaesthetic her middle ear was inspected and no abnormality seen. One week after the operation her balance was normal and the hearing loss continued at the $70 \mathrm{db}$ loss for the 4, 6 and $8 \mathrm{Khz}$ notes that she had pre-operatively. One month later she had the same deafness as ever with normal hearing in the unaffected ear.

The diagnosis in both these cases was a labyrinthine membrane rupture i.e. damage confined to the intra-cochlear region and herewith some references.

$$
\begin{aligned}
& \text { Yours faithfully, } \\
& \text { NOEL ROYDHOUSE }
\end{aligned}
$$

\section{REFERENCES}

Simmons, F. B., 1968 "Theory of membrane breaks in sudden hearing loss". Arch.Otolaryngol. 88: 41-8.

Goodhill, V., 1976 “Sudden sensorineural deafness". Proc.R.Soc.Med. 69: 565-72.

Roydhouse, N., 1981 "Sudden deafness and scuba divers" (correspondence). NZ.Med.J. 93: 131. 